\title{
Minecraft and coding in education: an overview of effect of gamification
}

Keywords: minecraft, game based learning, coding, computational thinking, computer science

\section{Opinion}

Teaching today has changed above all with the introduction of new technologies and with the use of some electronic devices that have transformed the way of teaching and the structure of the class.

The most effect on students learning derives mainly (but not only) from the Blended learning classrooms and therefore from the joint use of digital game-based learning in traditional teaching. The epochal change originates in the gradual advance of computational thinking in the teaching field up to the integration of coding in different platforms made available to users who have gone from the role of simple users to sometimes sophisticated creators of games and storytelling.

A noteworthy phenomenon is the appearance of interactive activities with games rooted in math and then also in other disciplines. Digital game-based learning (DGBL) and gamification, however, require different strategies: in the first case, there is a balance between in-class lessons and educational game play, in the second, the purpose is taking elements from games and adding them to lessons. These factors have determined the current success of Minecraft Education Edition up to the challenge between schools with positive results that can be observed online thanks to the sharing and synergistic work of educators and mentors (including myself with direct experiments to become part of this group as mentor for Italy) (Figure 1).

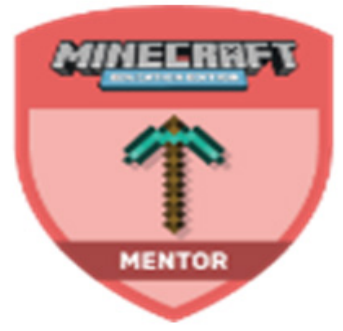

Figure I Minecraft Mentor Badge.

The success of MinecraftEducation ${ }^{1}$ Edition is due to the educational offer which turns out to be quite engaging for computer education thanks to the large group of features designed to help students learn the basics of programming and therefore to apply coding on STEM subjects and the flexible curriculum contributes to the development of computational thinking skills. In the online platform it is possible to discover conditions, functions, coordinates and everything that can be realized through Coding with Minecraft for students of different ages. Many lesson plans are available to everyone besides manuals designed specifically for students and there is no lack of assessment guides and Minecraft worlds. With Minecraft Education you can stay up to date with the rest of the world of game-based learning and that's
Volume 6 Issue I - 2020

\author{
Massimiliano Minaudo \\ University of Palermo, Italy
}

Correspondence: Massimiliano Minaudo, University of Palermo, Palermo, Italy, Email malcdo@ymail.com

Received: February 08, 2020 | Published: February 19, 2020

why the diffusion is now global. There are several objectives that can be achieved, for example, you can immediately start programming in Minecraft EE as an educator simply by installing the Code Connection plug-in on each student's computer, allowing them access and starting the program, leaving space for imagination and creativity to give life to very particular objects, the result of the genius with which they are certainly equipped.

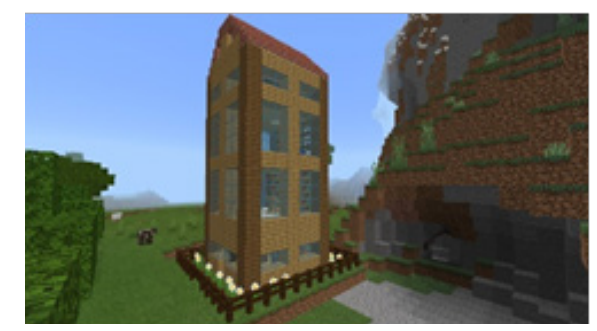

Figure 2 Minecraft construction.

You can challenge students, make them understand the basics of how to create scripts to control the agent to solve them. All this promotes the ability to solve problems. The publisher should always be the students to help them even if they have a tendency to solve mazes in their own way using your own logic (Figure 2).

Even children learn to program through the constant use of software and above all in a playful way. In Italy, a first free tutorial of 14 levels is available on the Code.org site to allow students to start getting familiar with the commands such as moving some small blocks related to command strings in order to then make the protagonists perform all the actions of the game, that is, how to program a real video game with the difference that there is entertainment. Code. org co-founder Hadi Partovi explained in a video the key elements of this initiative and how to involve young people by exploiting their passion for Minecraft. ${ }^{2}$ The CINI - National Interuniversity Consortium for Information Technology, since 2014 has provided to start the project Program the Future, in collaboration with MIUR - Ministry of Education, University and Research to try to provide schools with some fundamental tools related to the basic concepts of computer science, indeed, the country was among the first in the 
world to experience the introduction into schools of basic concepts of computer science with block programming and the project was rightly recognized as an initiative of European excellence for digital education in the context of the European Digital Skills Awards 2016.

\section{Conclusion}

To conclude, we can say that games certainly help students in classroom learning and it is correct to make the distinction between: video games (pure entertainment) and serious games (useful for teaching and to develop specific skills for students), in addition, there is a precise balance that must exist between this type of game to create something truly educational and fun for all students. Still wanting to clarify, DGBL continues to have a positive trend in terms of popularity and it is the most used by users. Having teachers, however, found excellent reasons to introduce the games in the classes on a weekly basis; however, some use them a little less but still monthly.

\section{Funding}

None.

\section{Acknowledgments}

None.

\section{Conflicts of interest}

The author declares that there was no conflict of interest.

\section{References}

1. B Brand JE, Kinash S. Crafting minds in minecraft. Education Technology Solutions. 2013;55:56-58

2. Duncan SC. Minecraft, beyond construction and survival. Well Played: a journal on video games, value and meaning. 2011;1(1):1-22. 